\title{
LAS TEORIAS CURRICULARES EN LOS PROGRAMAS CONTABLES: CASO UNIVERSIDAD DE CARTAGENA
}

\author{
GASPAR EDUARDO PALACIO MENDOZA* \\ MARIA EUGENIA NAVAS RIOS**
}

Recibido 25 de Junio de 2011/Enviado para Modificación 19 de septiembre de 2011/Aceptado 15 de Noviembre de 2011

\begin{abstract}
RESUMEN
El objetivo de esta investigación es analizar las teorías curriculares presentes en cada transformación del Programa de Contaduría Pública de la Universidad de Cartagena con el fin de identificar sus aportes a las diferentes estructuras curriculares resultantes, resaltándose los elementos determinantes que han definido cada una de las transformaciones curriculares, análisis que se considera pertinente para emprender procesos de mejoramiento continuo al interior del programa y de su formulación curricular, de tal manera que se logre una aproximación a la formación integral que demanda el contexto académico, disciplinar y social. Esta investigación se desarrolló desde un enfoque cualitativo, y es de corte descriptiva teniendo en cuenta que se pretende mostrar e identificar los enfoques y teorías curriculares presentes en cada transformación curricular del Programa de Contaduría Pública. Para el cumplimiento de los objetivos propuestos y teniendo en cuenta la naturaleza de los temas de análisis, se aplicaron técnicas de investigación cualitativa que facilitaron la recolección de la información, estas fueron, el análisis documental de los textos en donde se han consignado los diseños curriculares a lo largo del desarrollo del programa, los actos administrativos que normalizan y validan los diseños, y la técnica de entrevista a actores importantes dentro de los procesos de diseño curricular. A partir de la triangulación de información se obtuvieron las principales características de las cuatro transformaciones realizadas en el Programa de Contaduría Pública, siendo la más destacada la sujeción de los diferentes currículos a los referentes normativos disciplinares, a los contextuales como el sector empresarial y en el plano pedagógico, el seguimiento de modelos tradicionales, conductistas bajo un enfoque curricular técnico dando como resultado un currículo tipificado como técnico-científico.
\end{abstract}

\footnotetext{
* Docente Universidad de Cartagena - Programa de Contaduría Pública.

** Doctora en Educación. Docente Universidad de Cartagena. Correo Electrónico: mariaeunavas@yahoo.com
} 
Palabras claves: Teorías curriculares, reforma curricular, Educación Superior, Programas contables

Clasificación JEL: I20, I21, I23, M00, M41

\begin{abstract}
The main purpose of this research is to analyze the curriculum theories that were present in the transformation process of the Accountancy Degree Programme at Universidad de Cartagena, in order to identify the most important contributions to the different curriculum structures as a result of this process. Through an analysis of the information by categories, a wide range of interviews with associate lecturers, and through a comprehensive review of the normative framework related to the accountancy profession to the educational system and to the Universidad de Cartagena as institutional framework, were obtained the main and most significant characteristics of the four transformations that occurred in the programme of Public Accountancy: the strict connection with, the central disciplinary normative, with the context such as the entrepreneurial sector, and at the pedagogical level following traditional models known by their technical approach. By these reasons, the curriculum has been typified as a technicalscientific.
\end{abstract}

Key Words: Curriculum theories, Curriculum reform, Accountancy Degree Programmes, Undergraduate and Postgraduate Programmes

JEL Classification: I20, I21, I23, M00, M41

\title{
INTRODUCCIÓN
}

Ha sido una gran preocupación de la disciplina contable en el campo internacional en foros y seminarios, abordar el mejoramiento en la formación integral del profesional contable en lo que tiene que ver, principalmente, con su capacidad crítica ante los problemas de la sociedad de comienzos de milenio; con sus posibilidades de investigar y en general de trascender los aspectos meramente técnicos de su actuación, lo cual necesariamente implica procesos de transformación o de rediseños curriculares de los programas contables.

Los currículos se aceptan hoy en día como el resultado de un sistema dinámico, abierto y fluido. Este dinamismo se presenta por la múltiple y diversa gama de factores que influyen permanentemente en la realidad 
curricular y en la experiencia académica de los estudiantes. Los elementos que constituyen un currículo tienen varios orígenes, surgen de las normas y del marco legal; del entorno económico; de las tendencias pedagógicas, del desarrollo científico de una disciplina y especialmente de los significativos movimientos sociales y culturales. Esta naturaleza dinámica de los currículos obliga a continuas revisiones y análisis de tal manera que sea más probable garantizar la pertinencia de las propuestas curriculares y la calidad de la educación que se ofrece, Por otra parte, cada transformación curricular que se genera en un programa académico surge de una evidente ruptura del equilibrio en las necesidades de formación que el programa satisface, por lo que se hace necesario que los gestores, administradores y docentes identifiquen cuales son las fuentes de mayor impacto y pertinencia en los nuevos diseños curriculares que se proponen.

Una transformación curricular puede obedecer a diferentes y múltiples factores, entre ellas, el mismo Estado que plantea ciertos direccionamientos a través de las diferentes políticas, planes y proyectos educativos. Es por ello que en este trabajo se busca analizar cómo han incidido los enfoques y teorías curriculares en las reformas vividas hasta el momento en el programa de Contaduría Pública de la Universidad de Cartagena, haciendo un recorrido desde La Teoría Curricular asociada a las primeras manifestaciones de pedagogos norteamericanos sobre el tema del currículo, haciendo un recorrido por representantes importantes de este movimiento como John Dewey (1) quien consideraba que el currículo debería responder a las necesidades e intereses de los estudiantes, otros representantes de la escuela Norteamericana como Bobbit 1918, citado por Magendzo 1998, quien considera que la escuela norteamericana sobre currículo se asocia con el enfoque técnico conductual, que se caracteriza por ser racional, positivista, academicista, asignaturista y orientado a los resultados o eficientista. Características que han permeado a través del tiempo todas las transformaciones curriculares presentes en el programa de Contaduría Publica

Es importante considerar el significado que esta investigación representa para la ciencia contable, toda vez que sirve de marco referencial para aquellos programas y facultades que tengan contemplado o estén realizando transformaciones curriculares en el marco de las nuevas disposiciones sobre calidad académica y procesos de acreditación.

Por otra parte, la revisión teórica y conceptual que soporta el análisis curricular de las transformaciones del programa en estudio, se convierten en una actualización teórica y en una base conceptual tanto para lo 
curricular, para la formación docente, como para establecer líneas de acción y procedimientos inherentes a las futuras transformaciones curriculares que se deseen realizar.

\section{FUNDAMENTOS TEÓRICOS}

La llamada Teoría Curricular, también llamada Pedagogía Industrial debido a su fuerte asociación con los modelos económicos y sociales imperantes en la sociedad norteamericana de principios del siglo XX. Un significativo representante de este movimiento es John Dewey (1) quien consideraba que el currículo debería responder a las necesidades e intereses de los estudiantes, lo cual debía aplicarse fundamentalmente en la educación básica, en contraposición a Bobbit que se ubica en la misma escuela de la teoría curricular, pero que planteaba que el currículo debía basarse en las acciones del mundo adulto, es decir, en el perfil profesional y en el mercado de trabajo.

La escuela norteamericana, al tratar el tema del currículo se asocia con el enfoque técnico conductual, que se caracteriza por ser racional, positivista, academicista, asignaturista y orientado a los resultados o eficientista. El hombre desde esta escuela curricular es definido como "un actor en sociedad, un haz de actividades, un hacedor" (Bobbit 1918, citado por Magendzo 1998), es decir, es una concepción del currículo para la eficiencia social. Continuando el análisis bajo la percepción de Magendzo, se puede afirmar que bajo este enfoque curricular los docentes y los estudiantes desempeñan un rol específico. El papel del docente bajo este enfoque está orientado a ser un reproductor, un pasivo transmisor de lo que otros producen en una comunidad de expertos, es un evaluador de la información sin proyección pedagógica. A su vez, el estudiante prácticamente no es percibido como un actor importante en el proceso de enseñanza salvo en su capacidad de poder ser receptor y de estar en función de la tecnificación.

En el enfoque practico, el currículo se concibe como una manifestación de las intenciones educativas y su interacción con la sociedad y la cultura, comienza a ser planteado por Laurence Stenhouse en 1975 (2) cuando afirma que el currículo es un intento de comunicar una propuesta educativa, de tal forma que quede planteada y abierta a la discusión y el escrutinio crítico y pueda ser traducida efectivamente en la práctica a manera de contrastación, es decir, el currículo debe convertirse en una disciplina que estudie permanentemente las relaciones entre la teoría y las practicas educativas, entre estas y las sociedades y sus posturas políticas, 
por lo cual se afirma que el currículo es dinámico, debe ser una expresión de los movimientos, intenciones y dinámicas sociales, es decir, no debe ser concebido como un subsistema, sino como el resultado permanente de la interacción de los subsistemas sociales y de las instituciones educativas en donde se hace realidad. En términos de Magendzo Abraham (1991) el currículo sería entonces el proceso mediante el cual se selecciona, organiza y distribuye la cultura que debe ser aprendida.

El docente en el enfoque práctico curricular, es concebido como un profesional con capacidad de autorreflexión, la acción pragmática depende del trabajo reflexivo y deliberativo del docente. Según Stenhouse (2), el docente es un investigador, un creador de nuevas prácticas y nuevos pensamientos curriculares. El estudiante a su vez es un individuo que participa, reflexiona y desarrolla interacciones en el medio en el que aprende.

La postura de Stenhouse (2) comienza a asociarse con una concepción del currículo, en la perspectiva de la filosofía constructivista, la cual lo considera como una construcción humana en un determinado contexto social, político y cultural, e inscrito en unas condiciones particulares, sociales e históricas en las cuales se desarrolla. El currículo como construcción humana implica dinámica, evolución, flexibilidad y participación de sus actores: profesores, administradores y estudiantes.

Continuando con el análisis de las diversas tendencias que conceputalizan sobre el currículo es necesario hacer referencia a la Teoría Crítica, en cuyo marco se señala el reconocimiento de las complejas relaciones que existen entre el currículo, lo cual según esta teoría permite definir el currículo como una herramienta ideológica que favorece los intereses de unos grupos sociales sobre otros, es decir, es una estrategia de poder. Con estos planteamientos se identifican pedagogos como Freire, 1970, Foucault, 1979, Beyer y Apple, 1988; Pinar, Reynold, Slattery y Taubman, 1995. (Citados por Figueroa (3)).

Se puede afirmar, que la Teoría Crítica introduce en la concepción del currículo una síntesis de elementos culturales y sociales que son inherentes a las propuestas curriculares. Por lo anterior, Bourdieu (2001), plantea que el currículum es un arbitrario cultural, que está conformado por elementos de diversas conformaciones culturales y su carácter es el de una estructura dinámica o relativamente estable. El currículum como propuesta político educativa: se haya vinculado a los proyectos políticos sociales por los grupos que impulsan y determinan un currículo. 
Para el caso de la educación superior, los currículos deben permitir y propiciar un diagnóstico real del contexto, desde lo social, cultural, tecnológico, económico y moral. En palabras de Giovanni Iafrancesco (2003) en sus tertulias con maestros, afirma que el currículo debe "encontrar respuestas nuevas a las condiciones nuevas del continuo devenir", esto es, preparar a las personas para los continuos y seguros cambios en todos los ambientes, lo cual encierra unas responsabilidades trascendentales e históricas inherentes a la formación del docente, a las conceptualizaciones y contextualizaciones de la Educación Superior frente al desarrollo científico, tecnológico, y a las metodologías de transmisión del conocimiento.

Actualmente, se acepta que el currículo en todos los niveles debe facilitar la construcción del conocimiento, el aprender a aprender, la producción de nuevos saberes y por lo tanto debe fundamentarse en las dimensiones científicas, tecnológicas, metodológicas y axiológicas. Sólo desde estas dimensiones se puede lograr la integralidad de la formación, entendida esta como toda experiencia que intencionalmente o no sensibiliza al ser humano en su condición de un ser biopsicosocial trascendente, lo cual permite aceptar que "las dimensiones humanas deben inspirarle a la Educación la necesidad de atender los procesos de formación espiritual, cognoscitiva- cognitiva- intelectiva, psicobiológica, socioafectiva y comunicativa para permitir al ser humano ser, saber, saber hacer, sentir, expresar lo que es, sabe, saber hacer y siente" Iafrancesco (2000).

En esta dirección, se promueve concebir el ser humano como una unidad compleja que como ser de pensamiento y de acción con el conocimiento, es ser físico, biológico, psíquico, cultural, social, e histórico, como considera Morin, en los Sietes saberes necesarios en educación (1999), y es misión de la educación a partir de los currículos, integrar en el aprender de modo significativo la comprensión del ser humano como individuo y como sociedad, lo cual implica romper con la pedagogía centrada en la especificidad de las disciplinas y un ingente esfuerzo de la comunidad académica por comprender la complejidad humana, las incertidumbres y todo aquello que constituye obstáculos a la comprensión, con el fin de enseñar principios para afrontar los riesgos y lo inesperado y modificar su trayectoria en virtud del concomiendo adquirido y del aprendido en el camino de afrontar situaciones nuevas.

El currículo como construcción humana, no es una sumatoria de hechos o acciones organizadas en una secuencia, por el contrario, es una diversidad interconectada y compleja en cuanto a interacción social y gestión; un 
modelo adoptado de modo consciente, donde participan todos sus actores, según sus características. Esta posibilidad de dinamismo de la construcción curricular es la que permite la realización de reformas y transformaciones curriculares, de tal manera que pueda adaptarse a las necesidades y cambios contextuales.

En el mismo sentido de Amaya, Figueroa (2006) plantea que se puede aceptar como una realidad que la educación formal en la sociedad tiene más posibilidad de éxito, si se conduce a través de un proceso curricular sistemático en lugar de utilizar uno improvisado. La construcción curricular tiene que verse como una actividad dinámica que va ajustándose a las necesidades imprevistas de la sociedad, de lo contrario, como muchas veces ocurre, el resultado es opuesto a las intenciones.

En cuanto al currículo de la formación contable, varios autores coinciden en plantear que la enseñanza de la contabilidad tanto en Colombia como en otros países obedece claramente a necesidades de los sectores económico y empresarial, identificando el conocimiento en relación con su operacionalización en un contexto situado, es decir, se reconoce la necesidad de conocer en cuanto sirve para un hacer especifico. La formación de contadores está entonces marcada por elementos disciplinares. El origen de esta tendencia específica en la formación contable estaría dado según Noy (4) porque en su historia la contabilidad más que otras disciplinas surge de la necesidad de hacer elaboraciones técnicas inicialmente, y posteriormente teóricas de acuerdo a contextos sociales, económicos y políticos definidos.

En la disciplina contable, han prevalecido los elementos procedimentales que luego se llevan a teorías y es lo que permite la asociación con el común desarrollo de pensamiento concreto con el que se identifica a los contadores.

"El proceso de desarrollo disciplinar, sumado a las practicas pedagógicas afectó el desarrollo teórico, de hecho la aparición tardía de un estatus disciplinar y profesional de la contaduría, corrobora la orfandad del desarrollo teórico mostrado por la contabilidad a través de la historia" (4).

Ya Cubides en 1994 (5), había afirmado a manera de alertar sobre el estatus profesional de la contabilidad, que los contenidos de orden técnico, con énfasis en la capacitación y en el desarrollo de destrezas que garantizarán un perfil que se ajustará a los requerimientos de las empresas no podrían llamarse formación en todo el sentido de la palabra, sino mas 
bien capacitación de tendencia empírica y pragmática que no provee al estudiante de los componentes necesarios en la pauta profesional que exige la moderna dinámica de las profesiones.

La discusión sobre el estatus de la profesión contable y por ende de su forma de enseñarla, se centra en establecer la naturaleza cognoscitiva de la contabilidad, es decir, una reflexión epistemológica del conocimiento contable en términos de sus desarrollos, construcciones, y de sus elaboraciones que permitan posteriormente identificar el cuerpo teórico que la sostiene, por lo cual varios exponentes de la profesión contable proponen espacios académicos y de investigación, lo cual se espera se traduzca en influencias directas sobre los currículos contables.

Para Noy (4), en los currículos contables actuales se observa un marcado énfasis en lo matemático y económico, mientras que las áreas sociales, de investigación y de idiomas no se perciben fundamentales en la formación. El énfasis estructural se presenta también en lo legal y en la normatividad fiscal. El énfasis en lo procedimental se observa en las actualizaciones en sistemas de información lo que permite mayor oportunidad de inserción en el mercado laboral.

El Colectivo de Trabajo "Nosotros", constituido por los estudiantes de Contaduría Pública de la Universidad Nacional plantea en su ponencia "Los Retos de la Educación Contable frente a la construcción de lo Público" (6) la ausencia en la formación contable del sentido de lo Público, rasgo preponderante si se tiene en cuenta que el profesional contable da Fé Pública de sus actos y de los actos de los demás. Lo público se asume como la sumatoria de los intereses privados sin que esté mediado por un acuerdo social Uricoechea (2001) (7).

La reflexión acerca de lo público, implica brindar al estudiante sujeto del currículo de la Contaduría Pública la oportunidad de ser crítico, ser sujeto activo en la sociedad y en la construcción de lo público (8), es decir, entender que además de ser profesional es ciudadano y que la profesión también tiene un carácter social. Lo anterior implica

"necesidad de una reconfiguración de lo público alrededor de la formación de los contadores como sujetos sociales quienes se encuentran provistos de autonomía y fe pública, las cuales deben surgir del uso de la subjetividad, por cuanto su labor debe responder al interés público y no al interés de quienes los nombran en las organizaciones" (8). 
Sobre las reformas curriculares específicamente en la carrera contable, Guillermo Martínez Pino (9) afirma que son prácticas exóticas, dada su escasez y pobreza metodológica, por lo cual el investigador considera que se pierde la oportunidad de buscar alternativas para la solución de los múltiples problemas que afectan la enseñanza de la Contaduría Pública en el nivel de la educación superior. Al respecto afirma:

"Se renuncia a la posibilidad de ser nómada intelectual, al aceptar una rutina, un tiempo normalizado y un espacio petrificado. La cronología y secuencias asignaturales los ritmos de instrucción en una práctica aparente, los horario inflexibles y los calendarios, imponen el ritmo de la inercia académica a la usanza de un circuito que se cierra consuetudinariamente como una cadena de repetición. Lo que cuenta es el cumplimiento de esta circularidad en la que se halla inscrito el proceso instruccional contable, en donde no hay tiempo para innovar porque hay que cumplir el programa"

Para este investigador dela pedagogía contable, un nuevo proyecto curricular, construido de cara al nuevo milenio, debe hacer reconocimiento de estos obstáculos, debido a que una profesión y disciplina como la contable, al no ser teorizada, reflexionada y confrontada, difícilmente aportará cambios sustanciales a la construcción de los nuevos paradigmas económicos y sociales tal como corresponde al nuevo contexto de "aldea global".

\section{OBJETIVO DE LA INVESTIGACIÓN}

Analizar las teorías curriculares, presentes en cada transformación del Programa de Contaduría Pública de la Universidad de Cartagena con el fin de identificar sus aportes a las diferentes estructuras curriculares resultantes.

\section{METODOLOGÍA}

La investigación "Las teorías curriculares en los Programas Contables: caso Universidad de Cartagena" se desarrolló desde un enfoque cualitativo y descriptiva porque lo que se pretende es mostrar e identificar los enfoques y teorías curriculares presentes en cada transformación curricular del Programa de Contaduría Pública

Las técnicas empleadas para la recolección de la información, fueron, el análisis documental de los textos en donde se han consignado los diseños curriculares a lo largo del desarrollo del programa, los actos administrativos que estandarizan y validan los diseños, y la técnica 
de Entrevista a actores importantes dentro de los procesos de diseño curricular.

Luego de obtener la información mediante las técnicas descritas, se procedió a su organización de tal manera que se pudieran integrar los datos y realizar un análisis pertinente a la investigación. Inicialmente se consignó la información en tres matrices de doble entrada que se describen a continuación:

- Matriz de Análisis Curricular: en la cual en el eje vertical se establecen los enfoques y teorías curriculares y en el eje horizontal las transformaciones curriculares a partir de los diferentes diseños curriculares del Programa de Contaduría Pública.

- Matriz de Análisis Normativo: en la cual en el eje vertical se establecen los enfoques y teorías curriculares y en el eje horizontal los cambios normativos tanto a nivel general como institucional.

- Matriz de Análisis de Entrevistas: en la cual en el eje vertical se establecen los enfoques y teorías curriculares y en el eje horizontal los aportes de los directivos docentes a la información documental recolectada.

\section{ANÁLISIS Y RESULTADOS}

En cumplimiento del objetivo, Analizar las teorías curriculares presentes en cada transformación del Programa de Contaduría Pública de la Universidad de Cartagena, con el fin de identificar sus aportes a las diferentes estructuras curriculares resultantes se presentan las matrices de análisis obtenidas de las fuentes de información, esto desde los documentos curriculares, de las entrevistas realizadas a los directivos docentes del programa y del marco normativo orientador de las diferentes modificaciones curriculares.

El análisis realizado a los diferentes documentos, muestra como el enfoque técnico ha prevalecido por encima del práctico y el crítico. Representado específicamente por el carácter asignaturista como se presenta el plan de estudios, solo en la última reforma del programa 2004 (10) y obedeciendo a la normatividad, se presenta un componente electivo y flexible, el cual de forma tacita está promoviendo la autonomía, el libre desarrollo de la personalidad y el profesional desde su integralidad como ser humano.

Las entrevistas realizadas al director y ex-directores del programa, demuestran el predominio del enfoque técnico en el programa de 
Contaduría Pública de la Universidad de Cartagena desde su primera transformación, es similar a los resultados desde el análisis documental con la diferencia que los directores reconocen como desde la segunda reforma aparecen muy tímidamente los aspectos de formación integral de los profesionales en la Contaduría Pública; en la tercera reconocen la inserción de la investigación en el área contable y como estrategia de formación y por ultimo en la cuarta y última a la fecha, reconocen el impulso a la formación por competencias del contador, pero reconocen en forma expresa que este tipo de formación sigue siendo de carácter técnico.

Desde el análisis de la normatividad, se afirma que ésta, está presente de principio a fin en cada una de las reformas y por lo general es la misma norma la que produce la reforma curricular. Cada una de las reformas obedece a cada punto explicito en ella, esta afirmación se fundamenta en lo escritural que se aprecia en cuadros posteriores. Se destaca como en la última normatividad, de acuerdo a lo expresado en ella, se refleja en algunos aspectos cada una de las orientaciones curriculares estudiadas a la fecha y las cuales han servido de marco referencial en todo el trabajo. 


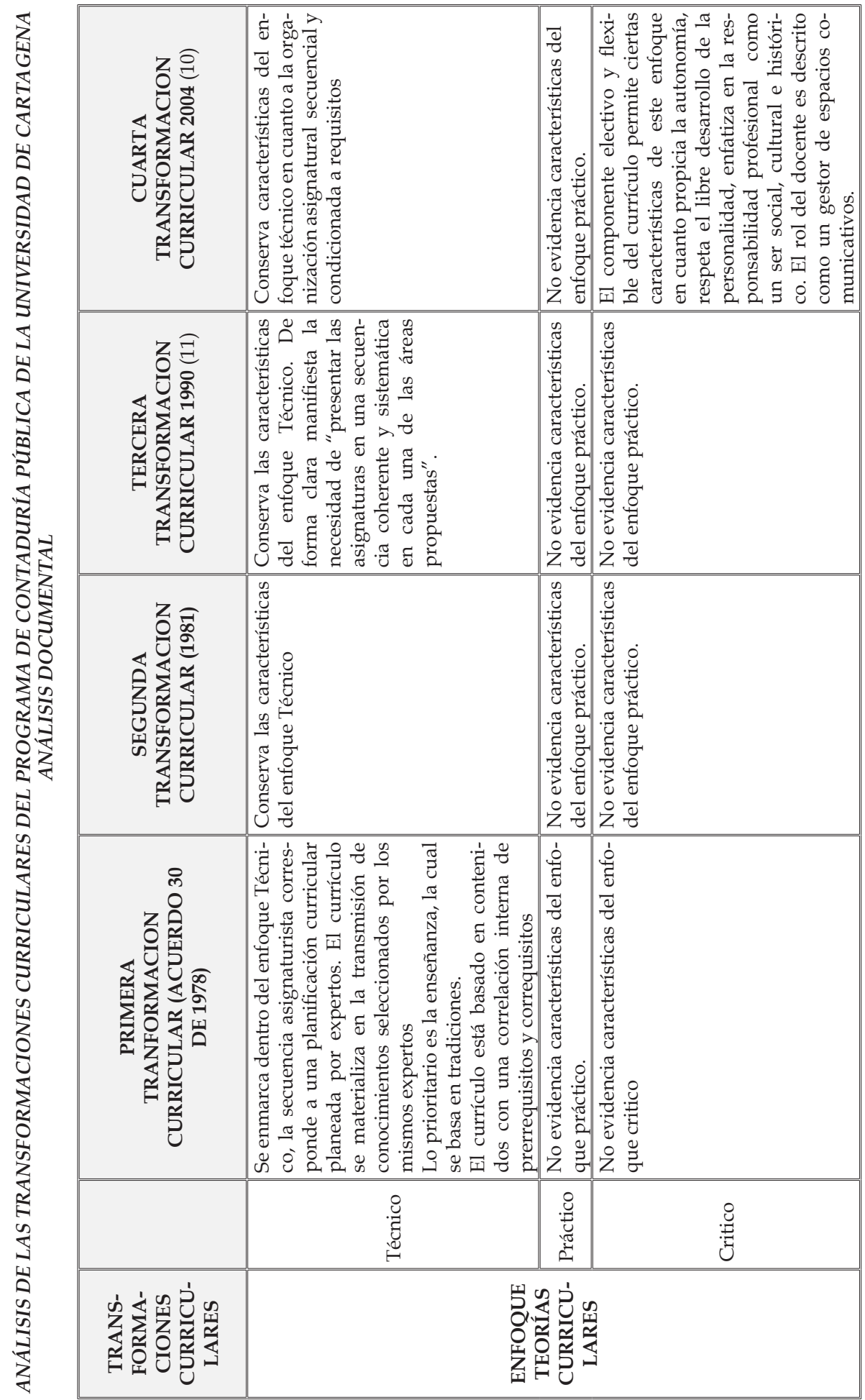




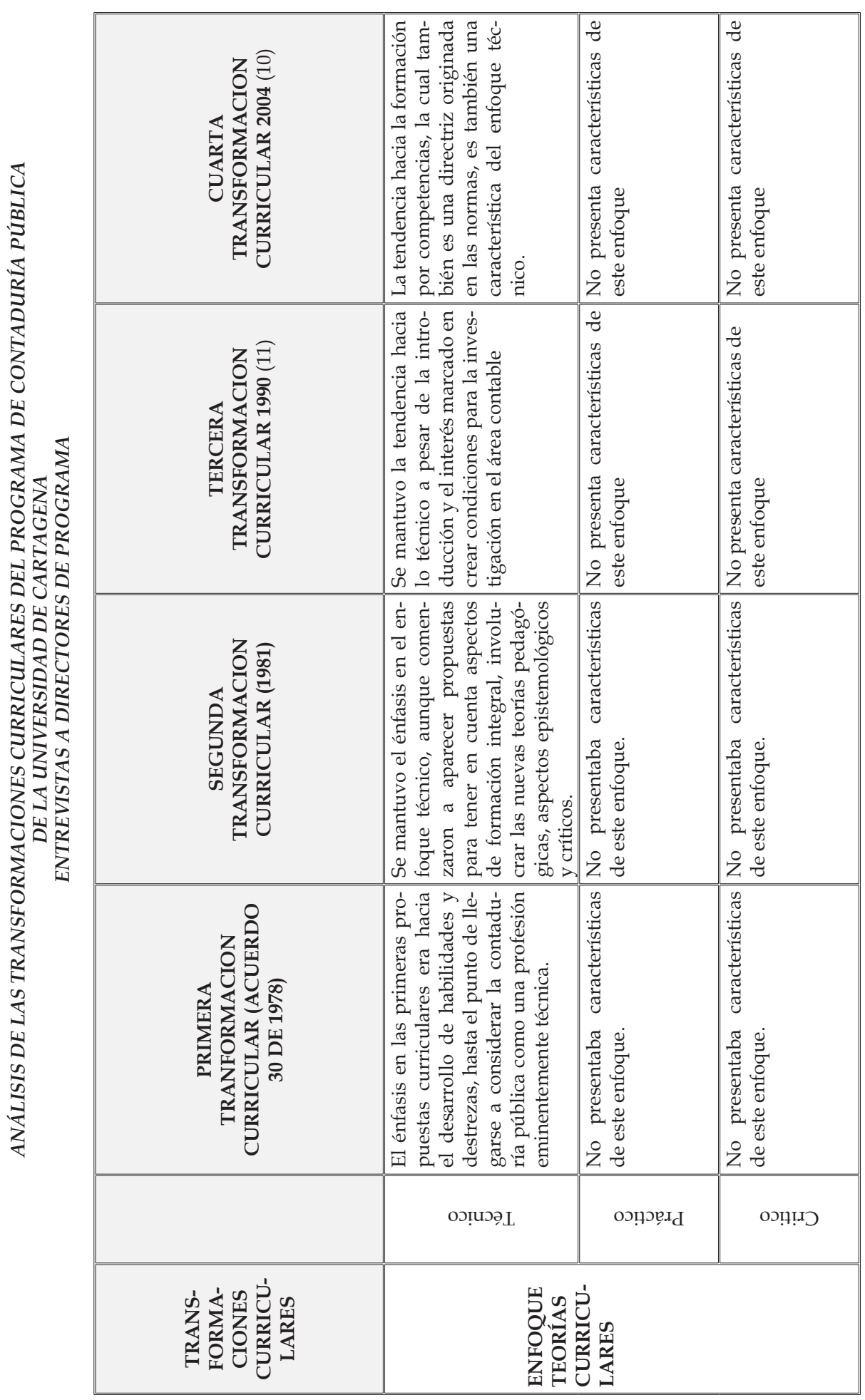




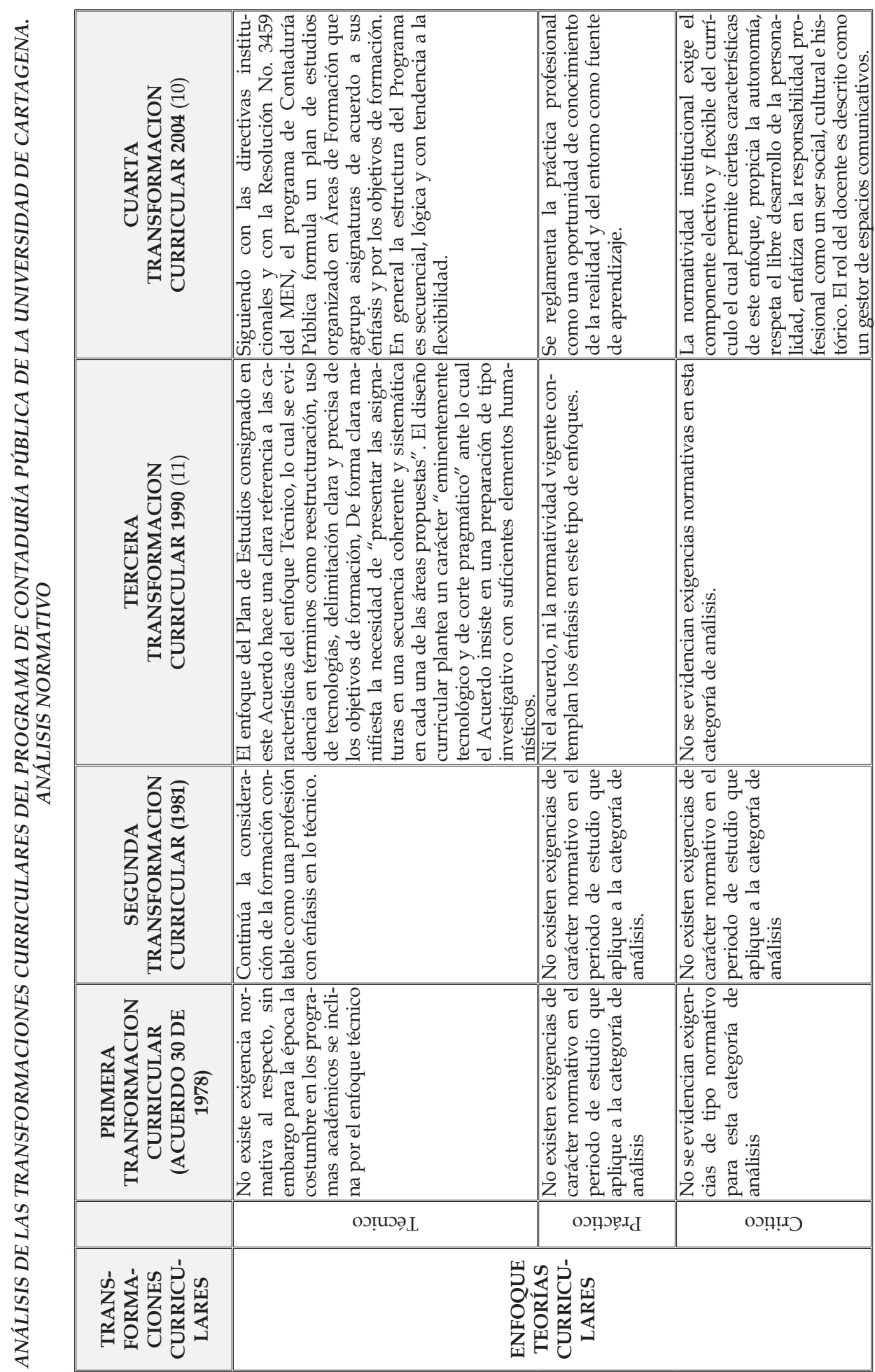




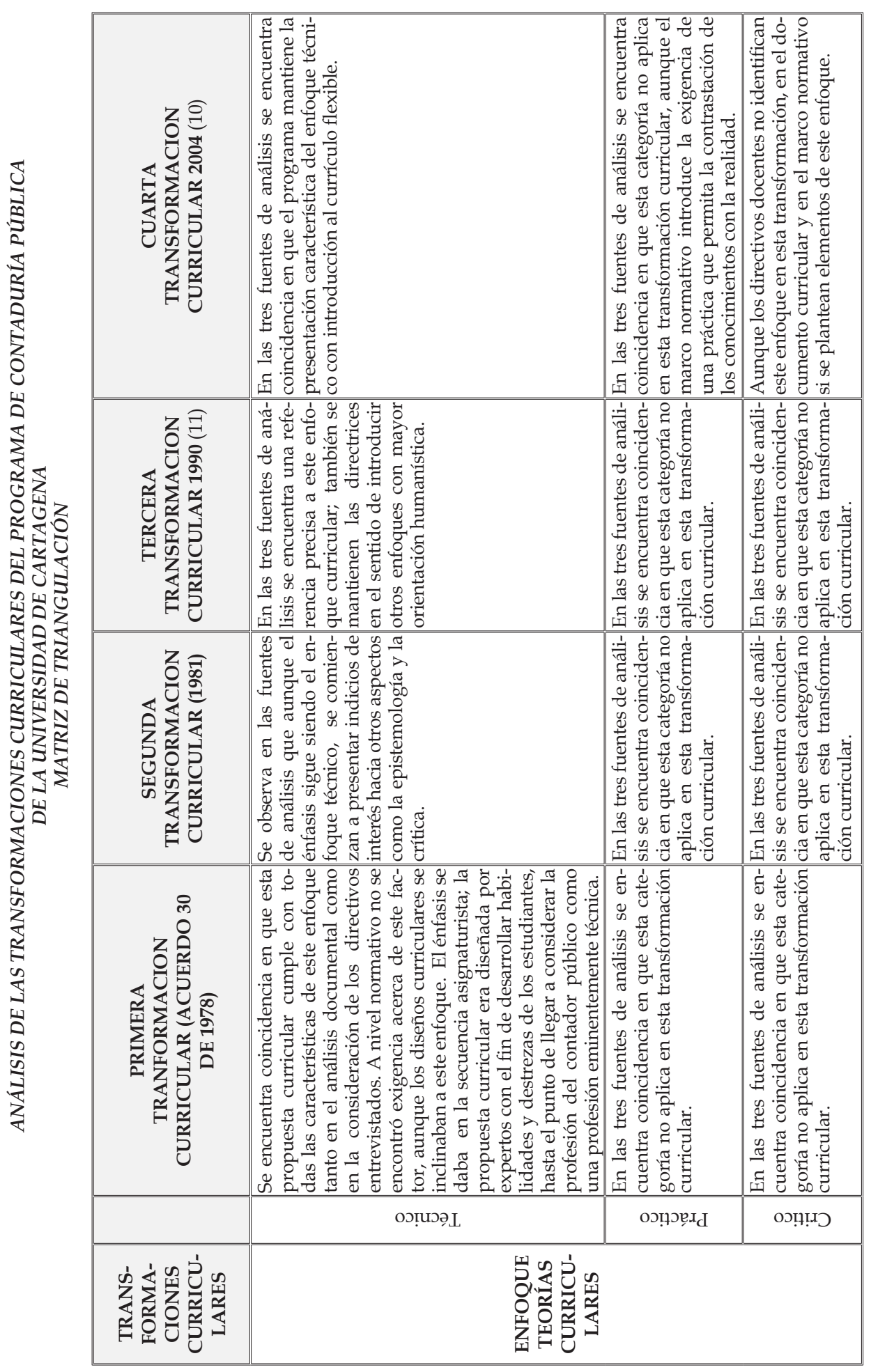


Al registrar los resultados obtenidos en cada una de las transformaciones curriculares del programa de Contaduría Pública de la Universidad de Cartagena, mediante la triangulación de la información obtenida de las fuentes objeto de consulta, encontramos que en la primera transformación curricular, en lo atinente a el enfoque o teoría curricular en la que se sustentaba el currículo programa de Contaduría Pública de la Universidad de Cartagena, existe unidad de criterios en que muy a pesar de no estar explicitado en el currículo las características de secuencia asignaturista, el énfasis en la enseñanza más que en el aprendizaje, un currículo basado en contenidos secuenciales y la correlación interna de requisitos y correquisitos demuestran que el enfoque curricular de esta primera transformación curricular se identifica con la teoría técnica, no obstante que el desarrollo teórico y técnico en los estudios sobre currículo no contemplaba estas categorías como sustento para el diseño curricular. $\mathrm{Al}$ respecto encontramos que la aproximación más relevante se observa en el planteamiento de objetivos específicos, los cuales estaban esencialmente encaminados al desarrollo de cada asignatura, sustentados en el Acuerdo 30 de 1978. Estos aspectos fueron ratificados al consultar las otras fuentes de información del análisis; es decir, que el planteamiento fue validado por la postura de los directivos docentes del programa de Contaduría Pública de la Universidad de Cartagena, así como también con el marco normativo correspondiente.

En el diseño curricular de 1978, se encuentran los factores o elementos que subyacen en el plan de estudios, donde se evidencia la influencia que para ese periodo histórico del programa de Contaduría Pública de la Universidad de Cartagena ejercía el entorno empresarial, como orientador en el proceso de formación de los profesionales contables, esto, dadas las características y necesidades de los diferentes sectores de la economía regional del momento donde las cualidades del contador público se perfilaban al "saber hacer", buscando siempre responder a las necesidades de información financiera del ente económico y dejando a un lado aspectos de vital importancia como la participación activa en el proceso decisional o expresado en palabras de Fernando Catadora Carpio que considera:

"Un Contador como un profesional integro que permite que los negocios en el mundo puedan entender el lenguaje de la contabilidad. Un profesional que con su visión de ética ayuda a cumplir con los deberes que las empresas tienen con sus accionistas y dueños. Un profesional que ayuda con su ejercicio profesional a la mayor transparencia de la información financiera para la toma de decisiones." 
En la segunda transformación del programa ocurrida en 1981 en relación con las teorías y enfoques curriculares sigue prevaleciendo el enfoque técnico como modelador de los diseños curriculares del programa, esto atendiendo a que los currículos con los cuales se educan a los contables, enfatizan en el saber técnico - instrumental que es un campo referido a la ejecución de un conjunto de destrezas y habilidades operativas desarrolladas para dar respuesta a las exigencias del mercado del trabajo (aplicaciones contables, finanzas, auditoria, entre otras), dejando a un lado la preocupación por una actividad no productiva preocupada por la ampliación del conocimiento en el orden de crear una base teórica y conceptual en cuanto a los saberes contables; es decir se ratifica la importancia dada por quienes diseñaron los currículos o los directivos docentes a la prevalencia de lo profesional sobre lo disciplinar, en lo cual también se observa el énfasis en la experiencia profesional de los docentes y en la fuerte influencia del gremio contable sobre las orientaciones académicas de los programas de formación en esta disciplina.

La tercera transformación curricular del Programa de Contaduría Pública (1990) (11) conserva características y tendencias similares a la propuesta curricular de la segunda transformación. Por ser previa a la Reforma Universitaria generada por la Ley 30 de 1992 no se observa la influencia de los cambios institucionales que con esta Ley se realizaron en la Universidad de Cartagena. Esta reforma enfatizó en cambios formales tales como la adopción de ulas académicas como unidades de medición y evaluación de la labor académica. Este aspecto formal fue definido por el Decreto 35666 de diciembre de 1980 que reglamenta el artículo 40 del Decreto Extraordinario 80 de 1980.

El enfoque técnico y los modelos; tradicional y conductista se continuaron considerando las bases conceptuales que le dan soporte al programa y que de acuerdo a su formulación son coherentes con los objetivos de formación del Programa, los cuales continúan siendo enfáticos en el desarrollo de habilidades, técnicas, conocimientos instrumentales y profesionalizantes del futuro egresado.

En la propuesta curricular aprobada mediante acuerdo 10 del 13 de Mayo del año 2004 (10), es decir, la cuarta transformación, donde se acogen directrices institucionales en el marco de un enfoque de calidad apoyado en las normas nacionales, específicamente en lo atinente al decreto 2566 emanado del gobierno nacional el 10 de septiembre de 2003 donde se establecen las condiciones mínimas de calidad para los programas académicos de educación superior y en las tendencias 
internacionales como las consagradas en el documento emitido por la UNESCO (12), donde se expresaron los cuatro pilares de la educación: aprender a conocer, aprender a hacer, aprender a vivir juntos y aprender a ser. Se formularon por primera vez de forma explícita los elementos constitutivos de la plataforma estratégica y filosófica del Programa de Contaduría Pública de la Universidad de Cartagena, como son: misión, visión, valores y principios, dándole forma a la estructura curricular.

En cuanto al enfoque teórico o teoría curricular que da soporte conceptual y pedagógico a esta transformación es importante anotar que en las fuentes de información consultadas, se observa coincidencia en que continúa prevaleciendo la marcada tendencia del enfoque técnico, dado que se encuentran expresadas las características más significativas de este enfoque teórico, tales como: la secuencia asignaturista, la planeación originada en los expertos, la transmisión secuencial y lógica de los conocimientos; el énfasis en la enseñanza y en las estrategias de transmisión que plantean una relación docente - estudiante basada en el conocimiento del docente, y currículos basados en contenidos. Sin embargo existe evidencia en el documento curricular y en las fuentes consultadas sobre la vinculación del concepto de flexibilidad, intentando configurar escenarios importantes para la problematización y producción de prácticas académicas modernas orientadas a la generación de nuevos vínculos y nuevas relaciones con los diferentes actores en el proceso de formación, dentro de un proceso de apertura y redimensionamiento de la interacción entre las diversas formas de conocimiento u objetos de aprendizaje.

En relación con los otros enfoques teóricos presentados en el marco conceptual, tales como el enfoque práctico y el crítico; en necesario anotar que en cuanto al práctico en el marco normativo introduce la necesidad de aplicar una práctica pedagógica que permita la contrastación de los conocimientos transmitidos a los estudiantes con la realidad, es decir un análisis de la realidad social y vivencia del contexto como escenario de aprendizaje, buscando que el estudiante aplique la reconceptualizacion, interpretación y simbolización durante el proceso de enseñanza.

En lo referente a la teoría critica el componente electivo y flexible del currículo en esta cuarta transformación, permite observar ciertas características de este enfoque en cuanto propicia la autonomía, respeta el libre desarrollo de la personalidad, enfatiza en la responsabilidad profesional como un ser social, cultural e histórico. El rol del docente en esta propuesta, es descrito como un gestor de espacios comunicativos, aunque lo planteado en el documento curricular del programa de 
Contaduría Pública en cuanto al papel del docente en el proceso de enseñanza amerita una reflexión profunda dado que se atraviesa por un proceso de transición de un enfoque eminentemente técnico a uno que vincule elementos de la teoría crítica y practica.

Finalmente en el año 2004 se acogen los lineamientos de la profesión contable estipulados en la Resolución 3549 de 2002 que define las condiciones de calidad para los programas de Contaduría Pública. Los directivos docentes reconocen también la influencia de la IFAC (International Federation of Accountants) como organismo orientador de la profesión y sus directrices sobre los currículos de los programas contables.

\section{CONCLUSIONES}

Es relevanter concluir que en las primeras reformas curriculares del Programa de Contaduría Pública lo que se consideraba una transformación realmente consistía en supresión o adición de asignaturas decididas desde el conocimiento experto de los docentes, y no obedecían a procesos de análisis internos o de investigación del entorno o en la necesidad de la revisión de los modelos y las practicas pedagógicas.

El programa de Contaduría Pública de la Universidad de Cartagena, se ha caracterizado por enmarcarse en el Enfoque Técnico como teoría curricular que le da soporte a los diseños de los planes de estudio desde su creación hasta la transformación realizada en el año 1990. Esto significa que el programa ha adquirido una identidad en la que se priorizan y destacan como objetivos de aprendizaje el desarrollo de destrezas y habilidades de tipo técnico y procedimental, lo que permite afirmar que ha estado en general cerrado o poco permeado a otros enfoques y teorías pedagógicas tanto en su conceptualización disciplinar como en sus prácticas pedagógicas.

Es importante considerar, que La Contaduría Pública en Colombia es una profesión altamente reglamentada, lo cual se hace evidente en las transformaciones curriculares del Programa en la Universidad de Cartagena como una fuente importante de insumo curricular. Esto ha determinado la supresión y adición de asignaturas y de diferentes énfasis de acuerdo a los requerimientos que el contexto le hace a la profesión. Lo anterior se plasma en los elementos filosóficos del Programa los cuales privilegian y destacan la necesidad de responder a las características de los sectores empresarial y social con profesionales idóneos, con las competencias exigidas por los diferentes sectores no solo a nivel de 
habilidades y destrezas, sino en cuanto a mayores exigencias de tipo intelectual y relacional.

Se observa, que lo anterior logra quedar plasmado en la propuesta curricular formulada en el año 2004 en la cual el Programa de Contaduría Pública recogen los elementos constitutivos de una reforma curricular actual, en este sentido, formula la necesidad de asumir otros enfoques o teorías curriculares y modelos pedagógicos, como el constructivismo, lo que genera mayores exigencias en cuanto a prácticas educativas, al desempeño de los docentes y de los estudiantes. Introduce nuevas fuentes curriculares tales como los compromisos internacionales y los objetivos del milenio con la Educación; exige el logro de estándares de calidad y la formulación de los elementos filosóficos que sirvan de guía para el desarrollo del Programa a través del currículo. Es decir plantea cambios sustanciales en relación con la forma como se realizaron las anteriores transformaciones curriculares del Programa.

Por ello es pertinente, propiciar al interior del Programa de Contaduría Pública de la Universidad de Cartagena una reflexión profunda que se oriente al mejoramiento continuo del programa teniendo en cuenta el análisis realizado a las diferentes transformaciones que desde sus orígenes hasta la del año 2004 se han efectuado al Programa, esta reflexión debe orientarse a la conceptualización y aplicabilidad de la teoría contemplada en el documento curricular diseñado, siendo necesario considerar que el currículo del Programa de Contaduría Pública debe proyectarse como construcción humana que como se ha planteado teóricamente no es una sumatoria de hechos o acciones organizadas en una secuencia, por el contrario, es una diversidad interconectada y compleja en cuanto a interacción social y gestión; un modelo adoptado de modo consciente, donde participan todos sus actores, según sus características. La asunción de este concepto permitirá la integración entre el carácter técnico y social de la disciplina y la búsqueda de estrategias pedagógicas para lograrlo.

\section{REFERENCIAS BIBLIOGRÁFICAS}

1. Westbrook, Robert B. JOHN DEWEY 1859-1952. 1-2, París: UNESCO - Oficina Internacional de Educación, 1993, Vol. XXIII.

2. Stenhouse, Lawrence. Investigación y Desarrollo del Currículo. Madrid : Ediciones Morata, 1984.

3. Figueroa Molina, Roberto. Las estructuras del currículo: una alternativa para el desarrollo humano integral. Barranquilla: Revista Stvdia, 2002, Vols. 2-3. 
4. Noy, Luz Amparo y Maldonado, Estella. Desde la educación Contable: Una visión del desarrollo contable. La Habana: IX Asamblea General de la ALAFEC, 2005.

5. Cubides, Humberto, y otros. Historia de la Contaduría Pública en Colombia Siglo XX. Bogotá: Universidad Central - Departamento de Investigaciones, 1994.

6. COLECTIVO DE TRABAJO "NOSOTROS". El reto de la Universidad, por la sociedad. Medellín: Universidad de Antioquia, 1999.

7. Uricoechea, Fernando. Lo público: historia y estructura. 1, Bogotá: Universidad Nacional de Colombia, 2001, Trans.

8. Amortegui, J y Sepúlveda, Y. Los Retos de la Educación Contable Frente a la Construcción de lo Público. Bogotá: Universidad Nacional de Colombia, 1999.

9. Pino Martínez, Guillermo. 5campus.org. 5campus.org - Contabilidad Internacional. [En línea] 2002. <http://www.5campus.org/leccion/ rediseno>.

10. Universidad de Cartagena- Programa de Contaduría Pública. Reforma Curricular. Cartagena: Universidad de Cartagena, 2004.

11. - . Reforma Curricular. Cartagena: Universidad de Cartagena, 1990.

12. UNESCO. Organización de las Naciones Unidas para la Educación la Ciencia y la Cultura. http:/ / www.unesco.org. [En línea] 9 de Octubre de 1998. http://www.unesco.org/education/educprog/wche/decla ration_spa.htm\#declaracion.

\section{BIBIOGRAFÍA RECOMENDADA}

Bordieu P, Passeron J.C, (2001) La Reproducción, Madrid, Ed Popular

Iafranceso, G. (2003), Nuevos fundamentos para la transformación curricular. Ed. Magisterio.

Malagón, Plata, L. (2006). El currículo: Dispositivo Pedagógico para la vinculación Universidad - Sociedad. De http://revista.iered.org/v1n1/ html/lmalagon.html

Martínez, Pino, G. (2004) Las incoherencias Epistémicas en los constructos científico contables, (2004), en línea] 5campus.org, Contabilidad Internacional <http: // www.5campus.org/leccion/estatuto, 2008.

Morín, E, (1999), Los siete saberes necesarios en la Educación. 
Uricoechea, Fernando. (1999). La Profesionalización Académica en Colombia. Historia, estructura y procesos. Tercer Mundo Editores. Bogotá.

Vera, A, Villalón M. (2005). La triangulación entre métodos cuantitativos y cualitativos en el proceso de investigación científica. Buenos Aires.

Villarini, A. y otros.- (1992). Principios para la integración del currículo. Edit. Dpto. de Educación ELA. Pto. Rico.

VILLARINI J, Á, (2000). El currículo orientado al desarrollo humano integral y al aprendizaje autentico. Organización para el fomento del desarrollo del pensamiento. Puerto Rico. 